\title{
Adverse events following school-based vaccination of girls with quadrivalent human papillomavirus vaccine in Slovenia, 2009 to 2013
}

M Šubelj ${ }^{12}$, V Učakar $^{1}$, A Kraigher ${ }^{1}$, I Klavs ${ }^{1}$

1. National Institute of Public Health, Centre for Communicable Diseases, Ljubljana, Slovenia

2. European Programme for Intervention Epidemiology Training (EPIET), European Centre for Disease Prevention and Control (ECDC), Stockholm, Sweden

Correspondence: Maja Šubelj (Maja.Subelj@nijz.si)

Šubelj M, Učakar V, Kraigher A, Klavs I. Adverse events following school-based vaccination of girls with quadrivalent human papillomavirus vaccine in Slovenia, 2009 to 2013. Euro Surveill. 2016;21(14):pii=30187. DOI: http://dx.doi.org/10.2807/1560-7917. ES.2016.21.14.30187

Article submitted on 04 April 2015 / accepted on 04 August 2015 / published on 07 April 2016

Adverse events following immunisation (AEFIs) with qHPV reported to the Slovenian AEFI Registry for the first four school years of the vaccination programme were analysed. We calculated annual reporting rates for 11-14 year-old vaccinees with AEFIs, using the number of qHPV doses distributed within the schoolbased vaccination programme as the denominator. Between September 2009 and August 2013, 211 AEFIs that occurred in 89 vaccinees were reported, a rate of 149.5 vaccinees with AEFI per 100,000 qHPV doses distributed. For five vaccinees, serious AEFIs (8.4 per 100,000 doses distributed) were reported. The highest reporting rates were for fatigue, headache, and fever $\left(\geq 38.0^{\circ}\right)(53.8,40.3$, and 35.3 per 100,000 qHPV doses distributed, respectively). As no AEFI resulted in permanent sequelae and they all were categorised as serious only due to the criterion of a minimum of one day of hospitalisation, this provides reassurance for the safety of our school-based HPV vaccination programme. Further AEFI surveillance is warranted to provide data for HPV vaccination programme monitoring and evaluation of its safety.

\section{Introduction}

Two vaccines against human papillomavirus (HPV) infection are currently licensed in Europe. In September 2006: the quadrivalent HPV vaccine (qHPV) (Silgard/ Gardasil), containing virus-like particles (VLPs) of the recombinant major capsid L1 protein of HPV types 6, 11,16 and 18, was licensed for the prevention of cervical, vaginal, and vulvar precancerous lesions, cervical cancer and genital warts (condyloma acuminata). The bivalent vaccine (Cervarix), containing VLP antigens for HPV types 16 and 18, was licensed for preventing precancerous cervical lesions and cervical cancer $[1,2]$ in September 2007. In February 2015, the nine-valent HPV vaccine (Gardasil 9), containing four HPV VLPs that are in the $\operatorname{HHPV}(6,11,16$, and 18$)$ plus five additional HPV VLP types $(31,33,45,52$, and 58), was recommended for approval in Europe for use in the prevention of cervical, vulvar, vaginal, and anal cancer, genital warts and precancerous lesions of the cervix, vulva, vagina, and anus [3]. Neither of the vaccines protect against HPV types for which the individual is already seropositive at the time of vaccination [4]. HPV vaccination programmes in 25 European countries are currently being conducted for adolescent girls with full or partial funding [5].

Within the Slovenian national immunisation programme, a three-dose intramuscular vaccination with single qHPV vaccine vials at 0,2 , and 6 months interval has been subsidised for adolescent girls aged 11-12 years since September 2009. The qHPV vaccination, financed through mandatory health insurance, was offered via the school-based vaccination programme, performed by school physicians. Vaccination coverage, measured as the ratio between the number of girls aged 11-12 years in the 6 th grade who received all three doses of qHPV and the number of eligible girls in the 6th grade (birth cohort of ca 10,000 girls) as reported by school physicians, was $48.7 \%$ and $55.2 \%$ in school years 2009/10 and 2010/11, respectively. In order to increase the vaccination coverage, in September 2011, vaccination with qHPV has been offered also to girls aged 13-14 years, if they have not been vaccinated previously.

Pre-licensure clinical trials of qHPV showed that most adverse events following immunisation (AEFIs) with qHPV have been temporary and mild or moderate in intensity $[6,7]$. The most common AEFI was injectionrelated local reaction $[8,9]$. Fever, nausea, vomiting, dizziness, myalgia and diarrhoea were the most commonly reported systemic symptoms $[8,10,11]$. Severe 
Reporting rates of vaccinees with adverse events following immunisation, overall and serious, according to school year, school-based vaccination of girls aged 11-14 years with quadrivalent human papillomavirus vaccine, Slovenia, 1 September 2009 to 31 August 2013

\begin{tabular}{|l|c|c|c|c|c|}
\hline \multirow{2}{*}{$\begin{array}{l}\text { School } \\
\text { year }\end{array}$} & $\begin{array}{c}\text { Number of } \\
\text { qHPV doses } \\
\text { distributed }\end{array}$ & \multicolumn{2}{|c|}{ All AEFI reports } & \multicolumn{2}{c|}{ AEFI reports with serious AEFI } \\
\cline { 4 - 6 } & 14,601 & 20 & $\begin{array}{c}\text { Rate per 100,000 } \\
\text { qHPV doses }\end{array}$ & Number $^{\mathrm{a}}$ & $\begin{array}{c}\text { Rate per 100,000 } \\
\text { qHPV doses distributed }\end{array}$ \\
\hline $2009 / 10$ & 14,640 & 22 & 137.0 & 1 & 6.8 \\
\hline $2010 / 11$ & 15,945 & 19 & 150.3 & 2 & 13.7 \\
\hline $2011 / 12$ & 14,334 & 28 & 119.2 & 0 & 0.0 \\
\hline $2012 / 13$ & & 195.3 & 2 & 14.0 \\
\hline
\end{tabular}

AEFI: adverse events following immunisation; qHPV: quadrivalent human papillomavirus vaccine.

${ }^{a}$ An individual with a single AEFI report may have more than one adverse event.

AEFIs, such as severe headache with hypertension and bronchospasm were described in $0.5 \%$ [8]. Pooled analyses of clinical trials involving almost 12,000 participants exposed to the qHPV vaccine did not identify an increased risk of chronic or autoimmune diseases overall [12]. However, these studies were not large enough to study individual conditions and that is why post-licensure monitoring of AEFIs using large population-based cohorts is necessary to develop evidence for overall safety assessment of any vaccine in order to ensure the safety of the vaccination programme and to maintain public confidence in the vaccine and its uptake [13-15].

In Slovenia, physicians are obliged to report all recognised AEFIs according to the Law governing the infectious diseases to the AEFI Registry at the National Institute of Public Health (NIPH).

Our objective was to summarise AEFIs with qHPV passive surveillance data for the first four years of the school-based vaccination programme targeting girls aged 11-14 years in order to evaluate the safety of our vaccination programme.

\section{Methods}

Design and study population

We conducted a retrospective observational study of all AEFIs reported to the AEFI Registry at the NIPH from September 2009 to August 2013 that were associated with qHPV vaccination of all Slovenian adolescent girls aged 11-14 years. AEFI was regarded as any untoward medical event temporally associated with vaccination (vaccine itself, its handling or its administration) regardless of whether causal association was suspected or not [16].

Because the AEFI Registry at the NIPH is a legally mandated surveillance system, institutional review board approval and informed consent were not required.

\section{Data collection}

We collected individual level information, using AEFI reporting forms, on AEFI predefined signs and/or symptoms such as injection site pain, erythema, oedema, fever $\left(\geq 38^{\circ} \mathrm{C}\right)$, fatigue, nausea, diarrhoea, headache, sleep disorders, maculopapular rash, anaphylaxis, meningitis, and any other signs, symptoms or laboratory results the reporting physician may think relevant. The forms also include information on the date of vaccination, time of AEFI occurrence, AEFI start/end date, treatment, outcome and possible sequelae, vaccinee (name, age, sex, address), the vaccine (brand name, batch number, manufacturer), date of report, and the reporting physician's identity. One of the authors (MS) coded all reported AEFIs according to the system organ class, using the Medical Dictionary for Regulatory Activities (MedDRA) used by the European Medicines Agency (EMA) and assessed reported AEFIs for seriousness using the World Health Organization (WHO) surveillance definitions $[16,17]$.

\section{Outcome definitions and ascertainment}

Serious AEFI was defined as any untoward event that resulted in death, was life-threatening, required inpatient hospitalisation or prolongation of existing hospitalisation, resulted in persistent or significant disability or incapacity, was a congenital anomaly or birth defect, or required intervention to prevent permanent impairment or damage. The single case causality assessment of all serious AEFIs was performed according to the new criteria published by WHO in 2013. Causality was categorised as consistent, indeterminate, inconsistent, and unclassifiable [16]. For causality assessment, additional clinical information was obtained on vaccination history (previous vaccination, prior $\mathrm{AEFI}$ ), relevant medical and treatment history (e.g. underlying disease, known allergies, concomitant medication), and associated event(s) (e.g. exposure to environmental toxins). The timing of the onset of symptoms, consistency or plausibility of symptoms with the known pharmacology and toxicology of the qHPV, and whether or not an alternative trigger was present were all considered [18-20]. Finally, all serious AEFIs were 
TABLE 2

Adverse effects following immunisation (symptoms and/ or signs), school-based vaccination of girls aged 11-14 years with quadrivalent human papillomavirus vaccine, Slovenia, 1 September 2009 to 31 August 2013

\begin{tabular}{|c|c|c|c|}
\hline $\begin{array}{l}\text { AEFls } \\
\text { Symptoms and/or } \\
\text { signs }\end{array}$ & Number & $\begin{array}{l}\% \text { of all } \\
\text { AEFls } \\
\text { reported }\end{array}$ & $\begin{array}{l}\text { Rate per } 100,000 \\
\text { qHPV doses } \\
\text { distributed }\end{array}$ \\
\hline Malaise & 32 & 15.2 & 53.8 \\
\hline Headache & 24 & 11.4 & 40.3 \\
\hline Fever & 21 & 10.0 & 35.3 \\
\hline Injection site pain & 21 & 10.0 & 35.3 \\
\hline $\begin{array}{l}\text { Injection site } \\
\text { swelling }\end{array}$ & 12 & 5.7 & 20.2 \\
\hline $\begin{array}{l}\text { Injection site } \\
\text { erythema }\end{array}$ & 12 & 5.7 & 20.2 \\
\hline Fatigue & 12 & 5.7 & 20.2 \\
\hline Sleep disorder & 10 & $4 \cdot 7$ & 16.8 \\
\hline Dizziness & 10 & 4.7 & 16.8 \\
\hline Syncope & 8 & 3.8 & 13.4 \\
\hline Nausea & 6 & 2.8 & 10.1 \\
\hline Rash & 6 & 2.8 & 10.1 \\
\hline Abdominal pain & 5 & 2.4 & 8.4 \\
\hline Pruritus & 3 & 1.4 & 5.0 \\
\hline Face erythema & 3 & 1.4 & 5.0 \\
\hline Pallor & 2 & 0.9 & 3.4 \\
\hline Thrombocytopenia & 2 & 0.9 & 3.4 \\
\hline Vomiting & 2 & 0.9 & 3.4 \\
\hline Seizures & 2 & 0.9 & 3.4 \\
\hline Diarrhoea & 2 & 0.9 & 3.4 \\
\hline Cough & 1 & 0.5 & 1.7 \\
\hline Facial contusion & 1 & 0.5 & 1.7 \\
\hline $\begin{array}{l}\text { Gilbert's syndrome } \\
\text { worsening }\end{array}$ & 1 & 0.5 & 1.7 \\
\hline Anaemia & 1 & 0.5 & 1.7 \\
\hline Myalgia & 1 & 0.5 & 1.7 \\
\hline Conjunctivitis & 1 & 0.5 & 1.7 \\
\hline Chest discomfort & 1 & 0.5 & 1.7 \\
\hline Tachycardia & 1 & 0.5 & 1.7 \\
\hline Tremor & 1 & 0.5 & 1.7 \\
\hline Migraine episode & 1 & 0.5 & 1.7 \\
\hline Palm oedema & 1 & 0.5 & 1.7 \\
\hline $\begin{array}{l}\text { Injection site } \\
\text { induration }\end{array}$ & 1 & 0.5 & 1.7 \\
\hline Tonsillitis & 1 & 0.5 & 1.7 \\
\hline Herpes zoster & 1 & 0.5 & 1.7 \\
\hline Otitis externa & 1 & 0.5 & 1.7 \\
\hline Ear pain & 1 & 0.5 & 1.7 \\
\hline Total & 211 & 100.0 & 354.5 \\
\hline
\end{tabular}

AEFI: adverse effects following immunisation; qHPV: quadrivalent human papillomavirus vaccine. assessed for unexpectedness. An unexpected/unusual AEFI was defined as any event that in its nature, severity, outcome, or frequency was not consistent with the AEFIs pre-specified in the summary of product characteristics for qHPV [16]. Reporting rates of vaccinees with AEFI (AEFI reports), using as the denominator the number of qHPV doses distributed to the school physicians conducting the vaccination programme for eligible girls provided by the vaccine supply division at the NIPH were calculated for the first four school-years after the qHPV vaccine was marketed.

\section{Results}

Between September 2009 and August 2013, the AEFI Registry at the NIPH received 89 reports of AEFIs with qHPV within vaccination programme, with a total of 211 AEFIs that occurred in girls aged $11-14$ years. Overall, 59,520 qHPV doses were distributed. The overall reporting rate was $149.5 \mathrm{AEFI}$ reports per 100,000 qHPV doses distributed and varied from the lowest 119.2 per 100,000 in the school year 2011/12 to the highest 195.3 per 100,000 in the school year 2012/13 (Table 1).

More than half of AEFIs (51.1\%) occurred after the administration of the first qHPV dose, $27.3 \%$ after the second, and $21.6 \%$ after the third qHPV dose.

On average there were two adverse events per one $\mathrm{AEFI}$ report (range $1-5$ ). Among all $\mathrm{AEFI}$ reports, $6.8 \%$ included only injection site reactions, $61.4 \%$ only systemic AEFIs, and $31.8 \%$ a combination of local and systemic AEFIs. Of the $211 \mathrm{AEFIs}$ reported, all were completely resolved.

The most frequently reported AEFIs among 165 (78.2\%) systemic events were malaise $(15.2 \%$ of all AEFIs reported), followed by headache (11.4\%) and fever (10.0\%). Among 46 (21.8\%) local events, injection site pain (10.0\%) and swelling (5.7\%) were the most frequently reported AEFIs (Table 2). Post-vaccination syncope, and seizures (associated with syncope), were reported in eight (9.1\%) and two (2.3\%) vaccinees, respectively.

According to system organ class classification of AEFIs with qHPV, general disorders and injection site reactions were the most frequent $(68.7 \%)$, followed by nervous system disorders (10.4\%) and gastrointestinal disorders (7.1\%).

Five vaccinees had a serious adverse event, corresponding to the overall reporting rate of 8.4 per 100,000 qHPV doses distributed. Annual reporting rates of serious adverse events varied from 0 to 14.0 per 100,000 qHPV doses distributed (Table 3). All vaccinees with serious AEFI were hospitalised for 1-3 days, and all of them stayed in hospital only for observation, thus fulfilling one of the criteria for serious AEFIs (Table 3). One of the serious AEFIs, a severe headache preceded by blurred vision that was diagnosed as migraine episode by the attending physician, 
Serious adverse events following immunisation, school-based vaccination of 11-14 year-old girls with quadrivalent human papillomavirus vaccine, Slovenia, 1 September 2009 to 31 August $2013(n=5)$

\begin{tabular}{|c|c|c|c|c|c|c|c|}
\hline $\begin{array}{l}\text { School } \\
\text { year }\end{array}$ & Age (years) & $\begin{array}{l}\text { AEFI following } \\
\text { dose number }{ }^{a}\end{array}$ & $\begin{array}{l}\text { Time to onset } \\
\text { of AEFI after } \\
\text { vaccination }\end{array}$ & $\begin{array}{c}\text { AEFI } \\
\text { symptoms and/or } \\
\text { signs }\end{array}$ & $\begin{array}{l}\text { Hospitalisation } \\
\text { (days) }\end{array}$ & $\begin{array}{l}\text { Expected } \\
\text { AEFI }\end{array}$ & $\begin{array}{c}\text { Causality } \\
\text { assessment }^{\text {b }}\end{array}$ \\
\hline $2009 / 10$ & 11 & 2 & o min & Seizures, syncope & 1 & Yes & Consistent \\
\hline 2010/11 & 11 & 1 & $\begin{array}{l}\text { Several } \\
\text { minutes }\end{array}$ & $\begin{array}{c}\text { Nausea, fatigue, } \\
\text { headache, pallor, palm } \\
\text { oedema, } \\
\text { tonsillitis }^{c}\end{array}$ & 1 & Yes & Consistent \\
\hline 2010/11 & 11 & 3 & Several hours & Migraine episode & 3 & No & Indeterminate \\
\hline $2012 / 13$ & 11 & 1 & $45 \mathrm{~min}$ & $\begin{array}{c}\text { Nausea, fatigue, } \\
\text { somnolence, dizziness }\end{array}$ & 1 & Yes & Consistent \\
\hline $2012 / 14$ & 11 & 1 & $5 \mathrm{~min}$ & Syncope & 1 & Yes & Consistent \\
\hline
\end{tabular}

AEFI: adverse effects following immunisation; min: minutes; qHPV: quadrivalent human papillomavirus vaccine.

a Recommended schedule is a three $0.5 \mathrm{~mL}$ dose series with second and third doses administered 2 and 6 months after the first dose.

b The single-case causality assessment according to the World Health Organization criteria (consistent, indeterminate, inconsistent, and unclassifiable).

c Tonsillitis was also reported but with no temporal relation to a vaccination (onset 3 days before vaccination).

was classified as unexpected/unusual, since migraine is not listed among expected AEFls with qHPV. This AEFI was classified as adverse event with indeterminate causal relation with qHPV. In the remaining four vaccinees, serious adverse events were classified as expected and to be consistently causally related to vaccination with qHPV.

\section{Discussion}

In the first four school years after the school-based qHPV vaccination of 11-14 year-old girls in Slovenia, nearly 57,000 qHPV doses were distributed. Although the observed overall reporting rate of AEFIs with qHPV was relatively high, the proportion of reported serious AEFIs was similar to those from other passive AEFI surveillance systems. All AEFIs categorised as serious (only due to the criterion of hospitalisation for at least one day) were transient and resolved completely 1-3 days after receiving a vaccine. No cases of anaphylaxis and autoimmune disorders were reported. Among the reported AEFIs, we observed few cases of syncope that were occasionally accompanied by a brief seizurelike event, relatively frequent headaches and fever, in contrast to relatively few injection-site conditions. A migraine episode was recorded, an unexpected $A E F I$ with qHPV.

The relatively high overall reporting rate of individuals with AEFIs (149.5 per 100,000 qHPV doses distributed) during the first four years of the Slovenian school-based vaccination programme in comparison to overall reporting rates published by the Vaccine Adverse Event Reporting System (VAERS) in the United States of America (US), from June 2006 to December 2008; Ontario's female school-based HPV programme, Canada, from September 2007 to December 2011; and the Pharmacovigilance Centre in the Valencian Community, Spain, from September 2007 to December
2011 of 53.9 per 100,000, 19.2 per 100,000, and 103 per 100,000, respectively, might at least in part be explained by the fact that in Slovenia, AEFIs are mandatorily reportable by all physicians, while in the abovementioned countries the reporting of AEFIs is voluntary [20-22].

The reporting rate of serious AEFIs per 100,000 doses distributed in Slovenia was higher in comparison to the reporting rates from the US and Canada (8.4 vs 3.3 and 1.5 , respectively) $[20,21]$. The lack of serious reports with sequelae, which are usually very rare, may simply be related to the relatively low absolute exposure.

Syncope, which may be considered a procedure- or anxiety-related $\mathrm{AEFI}$, was reported at similar reporting rates of ca 8-10 per 100,000 vaccine doses distributed as reported from the US, and Australia, but at a somewhat lower rate in comparison to the reporting rate from Spain (13.4 VS 17 per 100,000 qHPV doses distributed) [22-26].

Brief seizure-like events that can accompany syncopal episodes, secondary to transient hypoxia, with stiffening (tonic) movements and autonomic instability after vaccination with qHPV have been reported previously through VAERS and described in international case reports $[25,27]$. Reporting rate of seizures accompanying syncope after vaccination with GHPV in Slovenia was similar to the rates reported from Spain and Australia (3.4 vs 3.2 and 2.6 per 100,000 qHPV doses distributed, respectively) [22,25]. However, monitoring of qHPV occurred between 2006 and 2009, during which a total of 600,558 doses were administered in the Vaccine Safety Database (VSD) population, and no association between qHPV and seizures, whether recurrent or new onset was observed [14]. 
A relatively higher reporting rate of headache was reported in Slovenia in comparison to the US and Spain (40.3 per 100,000 qHPV doses distributed vs 4.1 and 23.5 , respectively), and relatively higher reporting rate of fever in comparison to the US (35.3 vs 0.4 per 100,000 qHPV doses distributed) $[20,22,27]$. In contrast, although local reactions are usually frequently reported AEFIs with qHPV that are generally of short duration and resolve spontaneously, in our analyses only one fifth of reports with AEFIs with qHPV involved local reactions, mainly pain and swelling [28]. Varying frequencies may be due to a presumably much lower probability that a vaccinee with mild AEFIs seeks medical care and the fact that in Slovenia AEFIs are reportable only by physicians.

With respect to the unexpected/unusual AEFI after the vaccination with $\mathrm{GHPV}$, a migraine episode possibly related to qHPV, migraine has, to the best of our knowledge, been so far reported as a possible AEFI only after the vaccination with the Ann Arbor strain live-attenuated influenza vaccine [29]. Moreover, it is well recognised that reporting of neuropathic pain syndromes such as migraine headaches as an AEFI with its uncertain aetiology and/or pathogenesis can be expected when a new vaccine is introduced into a population $[28,30]$.

The major limitation of our passive surveillance system is that it can only identify early warning signals, and can neither estimate the risk relative to an unexposed population nor exclude risks with certainty [13]. Since the vast majority of vaccinees with mild AEFIs are not likely to seek medical care and AEFIs are reportable only by physicians, under-reporting of non-serious adverse events is expected [31]. The under-reporting of certain AEFIs in our surveillance system in comparison to the results from clinical trials is to be expected, as in our system only AEFIs presented to physicians are reported, in comparison to the clinical trials which report on the entire study population. The frequencies observed in the clinical trial programme of qHPV were highest for injection-related local reactions, but the systemic AEFIs, such as headache, were observed in only $0.5 \%$ in comparison to our results, where the most commonly reported AEFIs were systemic (malaise and headache) $[8,9]$.

Generally, AEFI rates calculated using as the denominator the number of qHPV doses distributed to the school physicians conducting the vaccination programme for grade 6 and grade 8 girls need to be interpreted with caution, since vaccine distribution data do not provide accurate information about the numbers of vaccine doses actually administered [21]. However, we believe that the qHPV distribution data are a fairly good approximation of the number of qHPV doses actually administered, since the Unit for vaccine distribution at the NIPH issues qHPV vaccine to the school physicians in response to actual usage. Because only serious AEFIs were reported to the EudraVigilance database by EMA and due to resource constraints in Slovenia, causality assessment was performed only for serious AEFIs. Moreover, we have applied no specific case definitions for AEFIs. In parts of the US there is also the Vaccine Safety Datalink project, where vaccine registers are linked with data from, for example, VAERS and evaluations of safety concerns are made [31]. Data on notification rates for other vaccines for which there are solid estimates of rates of AEFIs in the literature allow us to be reassured about the satisfactory level of exhaustiveness of our passive vaccine-vigilance surveillance. Thus, in the period 2005-2014, the reporting rate of vaccine-related thrombocytopenia after the administration of measles-mumps-rubella (MMR) vaccine reported to our surveillance system was 2.5 per 100,000 doses of MMR vaccine distributed. Our findings correspond with the results from the study done in the US where MMR vaccine caused 2.5 cases of immune thrombocytopenia per 100,000 doses distributed [32]. However, linkage of hospital data to vaccine data is not possible in Slovenia as there is no vaccination registry. A capture-recapture study is also not possible as there is no alternative system for recording AEFIs. However, our passive AEFI surveillance system has the important strength of being universal and covers the whole target population [31].

\section{Conclusions}

Although our reporting rate of serious AEFIs was relatively high, none of the serious AEFls resulted in any residual disability or incapacity. In fact, all serious AEFls were categorised as such only due to the criterion of hospitalisation for at least one day, were transient and resolved 1-3 days after exposure to qHPV vaccine. Further post-licensure AEFI surveillance is necessary for continuous provision of reassurance for qHPV safety and to maintain confidence in the HPV vaccination programme.

\section{Conflict of interest}

The authors declare that they have no competing interests.

\section{Authors' contributions}

All authors made contributions to conception and design of the manuscript. MS contributed to acquisition of data and their analysis and interpretation. All authors participated in drafting the article and revising it critically for intellectual content, and gave final approval of the version to be submitted.

\section{References}

1. European Medicines Agency (EMA). European public assessment report (EPAR) for Gardasil. Summary of product characteristics. Updated 9 Mar 2016. Available from: http:// www.ema.europa.eu/docs/en_GB/document_library/EPAR Product_Information/human/000703/WC500021142.pdf

2. European Medicines Agency (EMA). European public assessment report (EPAR) for Cervarix. Summary of product characteristics. Updated 2 Dec 2015. Available from: http:// www.ema.europa.eu/docs/en_GB/document_library/EPAR_Product_Information/human/000721/WC500024632.pdf 
3. Centers for Disease Control and Prevention (CDC), Petrosky E, Bocchini JA, Hariri S, Chesson H, Curtis CR, Saraiya M, et al. Use of 9-valent human papillomavirus (HPV) vaccine: updated HPV vaccination recommendations of the advisory committee on immunization practices.MMWR Morb Mortal Wkly Rep. 2015;64(11):300-4.PMID: 25811679

4. Labadie J. Postlicensure safety evaluation of human papilloma virus vaccines.Int J Risk Saf Med. 2011;23(2):103-12.PMID: 21673418

5. European Centre for Disease Control and Prevention (ECDC). Vaccine Schedule. [Accessed 5 Dec 2015]. Available from: http://vaccine-schedule.ecdc.europa.eu/Pages/Scheduler.aspx

6. Lu B, Kumar A, Castellsagué X, Giuliano AR. Efficacy and safety of prophylactic vaccines against cervical HPV infection and diseases among women: a systematic review \& meta-analysis. BMC Infect Dis. 2011;11(1):13. DOI: 10.1186/1471-2334-11-13 PMID: 21226933

7. van Klooster TM, Kemmeren JM, van der Maas NA, de Melker HE. Reported adverse events in girls aged $13-16$ years after vaccination with the human papillomavirus (HPV)-16/18 vaccine in the Netherlands.Vaccine. 2011;29(28):4601-7. DOI: 10.1016/j.vaccine.2011.04.050 PMID: 21549785

8. Gonçalves AK, Cobucci RN, Rodrigues HM, de Melo AG, Giraldo PC. Safety, tolerability and side effects of human papillomavirus vaccines: a systematic quantitative review.Braz J Infect Dis. 2014;18(6):651-9. DOI: 10.1016/j.bjid.2014.02.005 PMID: 24780368

9. Kang S, Kim KH, Kim YT, Kim YT, Kim JH, Song YS, et al. Safety and immunogenicity of a vaccine targeting human papillomavirus types 6,11, 16 and 18: a randomized, placebocontrolled trial in 176 Korean subjects. Int J Gynecol Cancer. 2008;18(5):1013-9. DOI: 10.1111/j.1525-1438.2007.01123.x PMID: 17986242

10. Indian HPV Vaccine Study Group, Bhatla N, Suri V, Basu P, Shastri S, Datta SK, Bi D, et al. . Immunogenicity and safety of human papillomavirus-16/18 ASo4-adjuvanted cervical cancer vaccine in healthy Indian women.J Obstet Gynaecol Res. 2010;36(1):123-32. DOI: 10.1111/j.1447-0756.2009.01167.X PMID: 20178538

11. Khatun S, Akram Hussain SM, Chowdhury S, Ferdous J, Hossain F, Begum SR, et al. Safety and immunogenicity profile of human papillomavirus-16/18 ASo4 adjuvant cervical cancer vaccine: a randomized controlled trial in healthy adolescent girls of Bangladesh. Jpn J Clin Oncol. 2012;42(1):36-41. DOI: 10.1093/jico/hyr173 PMID: 22194637

12. Block SL, Brown DR, Chatterjee A, Gold MA, Sings HL, Meibohm A, et al. Clinical trial and post-licensure safety profile of a prophylactic human papillomavirus (types 6, 11 , 16, and 18) [1 virus-like particle vaccine. Pediatr Infect Dis J. 2010;29(2):95-101. DOI: 10.1097/INF.ob013e3181b77906 PMID: 19952863

13. Arnheim-Dahlström L, Pasternak B, Svanström H, Sparén P, Hviid A. Autoimmune, neurological, and venous thromboembolic adverse events after immunisation of adolescent girls with quadrivalent human papillomavirus vaccine in Denmark and Sweden: cohort study. BMJ. 2013 Oct 9;347:f5906.DOI: 10.1136/bmj.f5906 PMID: 24108159

14. Gee J, Naleway A, Shui I, Baggs J, Yin R, Li R, et al. Monitoring the safety of quadrivalent human papillomavirus vaccine: findings from the Vaccine Safety Datalink. Vaccine. 2011;29(46):8279-84. DOI: 10.1016/j.vaccine.2011.08.106 PMID: 21907257

15. Constantine NA, Jerman P. Acceptance of human papillomavirus vaccination among Californian parents of daughters: a representative statewide analysis.J Adolesc Health. 2007;40(2):108-15. DOI: 10.1016/j.jadohealth.2006.10.007 PMID: 17259050

16. World Health Organization (WHO). Causality assessment of an adverse event following immunization (AEFI). User manual for the revised WHO classification. Geneva: WHO; 2013. Available from: http://www.who.int/vaccine_safety/publications/aevi_ manual.pdfhttp://

17. Medical Dictionary for Regulatory Activities (MedDRA). Introductory Guide MedDRA Version 17.0. March 2014 Available from: http://www.meddra.org/sites/default/files/ guidance/file/intguide_17_o_english.pdf

18. Chao C, Klein NP, Velicer CM, Sy LS, Slezak JM, Takhar H, et al. Surveillance of autoimmune conditions following routine use of quadrivalent human papillomavirus vaccine. J Intern Med. 2012;271(2):193-203. DOI: 10.1111/j.1365-2796.2011.02467.X PMID: 21973261

19. Chao C, Jacobsen SJ. Evaluation of autoimmune safety signal in observational vaccine safety studies. Hum Vaccin Immunother. 2012;8(9):1302-4. DOI: 10.4161/hv.21268 PMID: 22871958

20. Slade BA, Leidel L, Vellozzi C, Woo EJ, Hua W, Sutherland A, et al. Postlicensure safety surveillance for quadrivalent human papillomavirus recombinant vaccine. JAMA. 2009;302(7):750-7. DOI: 10.1001/jama.2009.1201 PMID: 19690307

21. Harris T, Williams DM, Fediurek J, Scott T, Deeks SL. Adverse events following immunization in Ontario's female schoolbased HPV program.Vaccine. 2014;32(9):1061-6. DOI: 10.1016/j. vaccine.2014.01.004 PMID: 24440208

22. Rodríguez-Galán MA, Pérez-Vilar S, Díez-Domingo J, Tuells J, Gomar-Fayos ], Morales-Olivas F, et al. [Adverse reactions to human papillomavirus vaccine in the Valencian Community (2007-2011)]. An Pediatr (Barc). 2014;81(5):303-9. Spanish. DOI: http://dx.doi.org/10.1016/j.anpedi.2013.11.031 PMID:24582127

23. McKeon A, Vaughan C, Delanty N. Seizure versus syncope. Lancet Neurol. 2006;5(2):171-80. DOI: 10.1016/S14744422(06)70350-7 PMID: 16426993

24. Naleway AL, Gold R, Drew L, Riedlinger K, Henninger ML, Gee J. Reported adverse events in young women following quadrivalent human papillomavirus vaccination.J Womens Health (Larchmt). 2012;21(4):425-32. DOI: 10.1089/ jwh.2011.2895 PMID: 22229713

25. Crawford NW, Clothier HJ, Elia S, Lazzaro T, Royle J, Buttery JP. Syncope and seizures following human papillomavirus vaccination: a retrospective case series. Med J Aust. 2011;194(1):16-8.PMID: 21449862

26. National Center for Immunization and Respiratory Diseases, Kroger AT, Sumaya CV, Pickering LK, Atkinson WL. General recommendations on immunization ... recommendations of the Advisory Committee on Immunization Practices (ACIP).MMWR Recomm Rep. 2011;60(2):1-64.PMID: 21293327

27. Agorastos T, Chatzigeorgiou K, Brotherton JM, Garland SM. Safety of human papillomavirus (HPV) vaccines: a review of the international experience so far.Vaccine. 2009;27(52):7270-81. DOI: 10.1016/j.vaccine.2009.09.097 PMID: 19799849

28. Macartney KK, Chiu C, Georgousakis M, Brotherton JM. Safety of human papillomavirus vaccines: a review.Drug Saf. 2013;36(6):393-412. DOI: 10.1007/S40264-013-0039-5 PMID: 23637071

29. Baxter R, Toback SL, Sifakis F, Hansen J, Bartlett J, Aukes $\mathrm{L}$, et al. A postmarketing evaluation of the safety of Ann Arbor strain live attenuated influenza vaccine in adults 18-49 years of age. Vaccine. 2012;30(20):3053-60. DOI: 10.1016/j. vaccine.2012.02.080 PMID: 22425787

30. Siegrist CA, Lewis EM, Eskola J, Evans SJ, Black SB. Human papilloma virus immunization in adolescent and young adults: a cohort study to illustrate what events might be mistaken for adverse reactions. Pediatr Infect Dis I. 2007;26(11):979-84. DOI: 10.1097/INF.ob013e318149dfea PMID: 17984802

31. Netterlid E, Månsson ME, Håkansson A. Surveillance of vaccine safety: comparison of parental reports with routine surveillance and a clinical trial.Vaccine. 2009;27(14):2042-7. DOI: 10.1016/j.vaccine.2009.01.131 PMID: 19428828

32. France EK, Glanz J, Xu S, Hambidge S, Yamasaki K, Black SB, et al. Risk of immune thrombocytopenic purpura after measlesmumps-rubella immunization in children. Pediatrics. 2008 Mar;121(3):e687-92. PMID: 18310189

\section{License and copyright}

This is an open-access article distributed under the terms of the Creative Commons Attribution (CC BY 4.0) Licence. You may share and adapt the material, but must give appropriate credit to the source, provide a link to the licence, and indicate if changes were made.

This article is copyright of the authors, 2016. 